\title{
$100 \%$ FOUNDRY COMPATIBLE PACKAGING AND FULL WAFER RELEASE/DIE SEPARATION TECHNIQUE FOR SURFACE MICROMACHINED DEVICES
}

\author{
Andrew D. Oliver ${ }^{1}$ and Carolyn M. Matzke ${ }^{2}$ \\ (1) Electromechanical Engineering and (2) Microsensor R\&D Departments \\ Sandia National Laboratories \\ Albuquerque, NM 87185
}

\begin{abstract}
A completely foundry compatible chip-scale package for surface micromachines has been successfully demonstrated. A pyrex (Coming 7740) glass cover is placed over the released surface micromachined die and anodically bonded to a planarized polysilicon bonding ring. Electrical feedthroughs for the surface micromachine pass underneath the polysilicon sealing ring. The package has been found to be hermetic with a leak rate of less than $5 \times 10^{-8} \mathrm{~atm} \mathrm{~cm} / \mathrm{s}$. This technology has applications in the areas of hermetic encapsulation and wafer level release and die separation.
\end{abstract}

\section{INTRODUCTION}

This paper reports the development of a technology that solves two fundamental problems in the area of surface micromachining. These problems are the lack of a small scale hermetic packaging technology and the need to do die level release.

Small scale hermetic packages have received some attention in the MEMS community. Work at the University of Michigan [12] and Delphi-Delco [3] among others has demonstrated that small glass on chip packages are both possible and hermetic [2].

However, these processes are either custom foundry processes, not available to outside users, or involve post processing steps on the silicon substrate itself. The work described here uses the released die with the self aligned monolayer anti-stiction coating from the publicly available Sandia National Laboratories SUMMiT IV process [4]. The die is bonded to the machined pyrex lid at $320^{\circ} \mathrm{C}$ and $-1500 \mathrm{~V}$ with no intermediate steps.

Die level release and handling is also a problem for surface micromachines. Many surface and bulk micromachined devices cannot be diced after the release process and thus cannot be released on a wafer level. This process allows the surface micromachined devices to be released and bonded on a wafer level. After the glass is bonded to the silicon, the packaged devices can be diced without damaging the surface micromachine.

\section{DESIGN}

To anodically and hermetically bond glass to silicon, a flat bonding area is required. The bonding area must be flat within $50 \mathrm{~nm}$, be large enough for the bond to withstand external loads, and have provisions for electrical leads to traverse beneath or through the bonding area. In this technology, the bonding ring and the electrical feedthroughs are both constructed of polysilicon. The electrical feedthrough is constructed of the poly0 layer that is $0.3 \mu \mathrm{m}$ thick. Next, $2 \mu \mathrm{m}$ of sacrificial oxide (sacoxl) is deposited which serves to electrically insulate and mechanically separate the electrical feedthrough from the polysilicon, which is subsequently deposited. The sacox 1 layer also serves to hermetically seal the area around the feedthrough. The sacrificial layer is exposed to the release etch at the edge of the bonding region, but because the release etch is of limited duration, less than $60 \mu \mathrm{m}$ of sacrificial oxide is lost on both ends of the feedthrough. This leaves more than $280 \mu \mathrm{m}$ of oxide to seal the serpentine feedthrough. The poly1, poly2, sacox3, and poly3 layers are deposited above the sacrificial oxide layer and serve to planarize the bonding region. The bonding area is $200 \mu \mathrm{m}$ wide and has a surface area of $3.2 \times 10^{-6} \mathrm{~m}^{2}$. A top view of a die with a glass micropackage is shown in Figure 1 and a cross section of the electrical feedthrough is shown in Figure 2.

\section{FABRICATION}

This paper reports on an extension of the SUMMiT IV technology which has been discussed previously [4]. One key advantage of the SUMMiT IV process is that the top level of polysilicon is planarized and does not reflect the topology of the underlying layers. For this device, the surface roughness of the bonding surface above the feedthroughs is less than $5 \mathrm{~nm}$. This very flat bonding surface reduces the temperature, time and voltage needed to make the seal.

After the wafers are fabricated, released, and coated with an anti-stiction coating, they are placed on the anodic bonding station and bonded. The anti-stiction coating does not appear to effect the bonding and appears to remain both on the bonding surface and on the moving structures after the bonding process. The bonding conditions are a temperature of $320^{\circ} \mathrm{C}$, a voltage of $-1500 \mathrm{~V}$, and a bonding time of five minutes. At the end of the allotted time, the voltage is turned off and the devices are removed from the hot plate.

\section{EXPERIMENTAL RESULTS}

One worry throughout this project has been that the electrostatic forces during the anodic bonding process would damage the surface micromachined devices. This problem was minimized by mechanically recessing the inside of the cover by $250 \mu \mathrm{m}$. This reduces the electrostatic force on the released micromachined parts by a factor of 2500 from a $5 \mu \mathrm{m}$ recess. The comb drives, shown in Figure 3, operated normally after bonding.

The leak rates of the bonded cavities have been measured with a He fine leak detector. The samples were "bombed" with He at a pressure of 3 atmospheres absolute and an exposure time of 2 hours. The samples, which have a volume of $3.6 \times 10^{-3} \mathrm{~cm}^{3}$, were then removed from the pressurized chamber and placed in a chamber connected to a mass spectrometer. Using this system, the He leak rate from the samples was measured for 7 out of 9 samples at less than $5 \times 10^{-8} \mathrm{~atm}$ atm $\mathrm{cm}^{3} / \mathrm{s}$. The equivalent standard leak rate in air is less than $1.1 \times 10^{-8} \mathrm{~atm} \mathrm{~cm}^{3} / \mathrm{s}$. Of the two samples that failed, one had a crack across the bonding interface and the second was not fully sealed. The leak rate for the remaining samples is smaller than the resolution of the machine.

Prior to and after the leak checking, some of the samples were diced. The dicing operation did not influence either the mechanical structure of the surface micromachines or their leak rate.

Attempts to characterize the bond strength between the polysilicon and glass were made by separating the glass from the silicon by means of a razor blade. In many places, the glass fractured and remained on the silicon although there was an 
isolated instance of a silicon piece remaining attached to the glass. Because the bonding area is only $3.2 \times 10^{-6} \mathrm{~m}^{2}$, there were also many places where the bond broke at the interface. Interestingly, there did not seem to be a great deal of difference in bond strength between the samples that were supercritically dried and those that were coated with the self aligned monolayer anti-stiction coating. Figure 4 shows a glass fragment on a polysilicon bonding ring sample that was coated with anti-stiction coating before bonding.

\section{CONCLUSION}

A hermetic, completely foundry compatible surface micromachine chip-scale package has been developed. The package also allows the surface micromachine to be diced after the release step. A recessed glass cover is placed over the surface micromachined die and anodically bonded to a planarized polysilicon bonding surface. The package leak rate has been measured to be less than $5 \times 10^{-8} \mathrm{~atm} \mathrm{~cm}^{-3} / \mathrm{s}$ for helium.

\section{ACKNOWLEDGMENTS}

The authors would like to thank John McBrayer, Peggy Clewes, Steve Garrett, Kent Schubert, David Plummer, the staff of the Microelectronics Development Lab, Compound Semicondutor Research Lab, and the Electromechanical Engineering Department for their help on this project. Sandia National Laboratories is a multi-program laboratory operated by the Sandia Corporation, a Lockheed Martin Company, for the United States Department of Energy under contract DE-AC04-94AL8500.

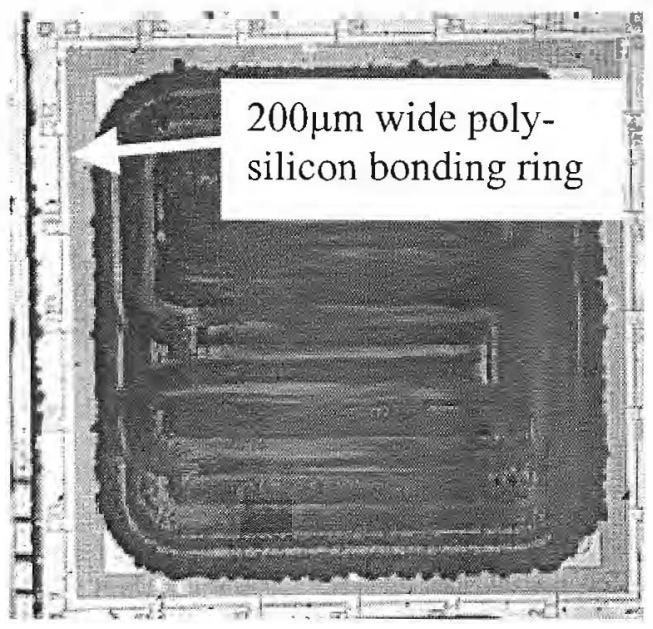

Figure 1. Surface micromachined device with glass cap. The black areas are caused by the surface roughness of the glass where it was milled to create the recess. The die size is $4.6 \mathrm{~mm} \times 4.6 \mathrm{~mm}$.

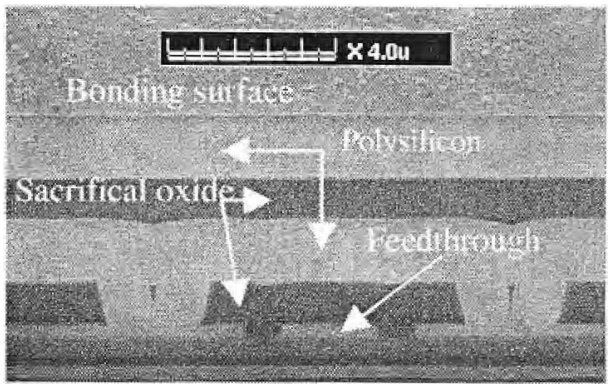

Figure 2. Cross-section of feedthrough. The light gray areas are polysilicon and the dark areas are sacrificial oxide.
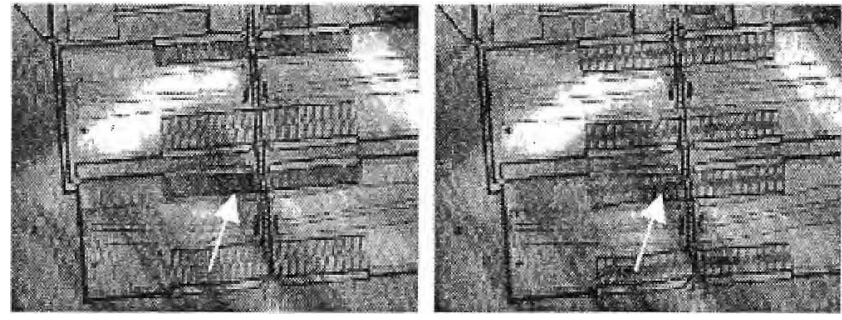

Figure 3. Comb drive operating beneath glass cap. The arrows point out the movement of the comb drives. The fuzzy diagonal lines are artifacts of the machining process used to create the cap.

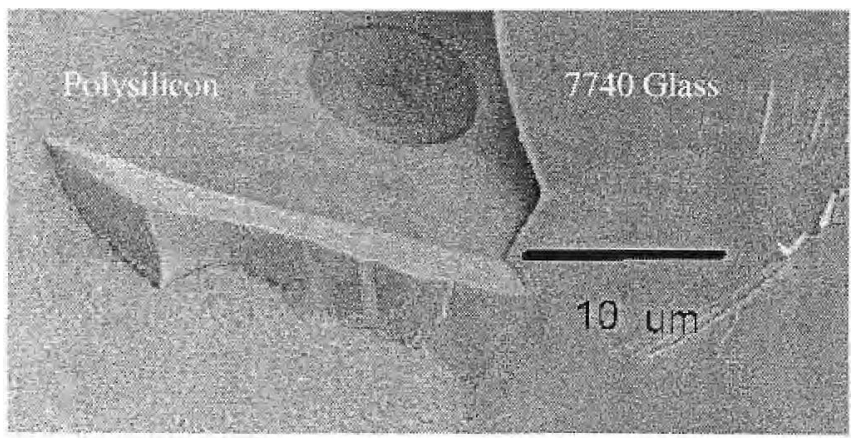

Figure 4. Glass left on polysilicon bonding region after the bond was separated using a razor blade. This sample as supercritically dried. The recess in the top center is an alignment aid.

\section{REFERENCES}

1. Y. T. Cheng, L. Lin, and K. Najafi, "Localized Silicon Fusion and Eutectic Bonding for MEMS Fabrication and Packaging", Journal of Microelectromechanical Systems, vol. 9, no. 1, pp. 3-8, 2000

2 B. Ziaie, J. A. von Arx, M. R. Dokmeci, and K. Najafi, "A Hermetic Glass-Silicon Micropackage with High-Density On-Chip Feedthroughs for Sensors and Actuators", Journal of Microelectromechanical Systems, vol. 5, no. 3, pp. 166-179, 1996.

3. D. Sparks, D. Slaughter, R. Beni, L. Jordan, M. Chai, D. Rich, J. Johnson, and T. Vas, "Chip-Scale Packaging of a Gyroscope Using Wafer Bonding”, Sensors and Materials, vol. 11, no. 4, pp. 197-207, 1999.

4. H. Schriner, B. Davies, J. Sniegowski, M. S. Rodgers, J. Allen, and C. Shepard, "Sandia Agile MEMS Prototyping, Layout Tools, Education and Services Program", 2nd International Conference on Engineering Design and Automation, Maui, Hawaii, 1998. 